\title{
Alterations of Coronary Perfusion Pressure and Cardiac Contraction during Lipopolysaccharide Challenge
}

\author{
J. Tu ${ }^{1}$, Q-X. Shan ${ }^{1}$, H-F. Jin ${ }^{1}$, I.C. Bruce ${ }^{2}$, Q. Xia ${ }^{1}$ \\ ${ }^{1}$ Department of Physiology, Zhejiang University School of Medicine, Hangzhou; ${ }^{2}$ Department of Physiology, The \\ University of Hong Kong, Hong Kong, China \\ E-mail: xiaqiang@zju.edu.cn
}

\begin{abstract}
In the present study, we used the Langendorff technique to evaluate the involvement of endothelin-1 (ET-1) and nitric oxide (NO) in coronary vasoconstriction and myocardial depression in hearts isolated from lipopolysaccharide (LPS)-treated rats. Coronary perfusion pressure (CPP) increased markedly in hearts from LPS -treated rats. Pretreatment with BQ-123, an ET-1 type A receptor antagonist, significantly reduced the increase in CPP induced by LPS. LPS induced a marked decrease in left ventricular developed pressure, the product of left ventricular developed pressure and heart rate, as well as the maximal rate of rise/fall of left ventricular pressure. Pretreatment with BQ-123 partially reversed the LPS-induced cardiac depression. Administration of BQ-123 and AMG, an inhibitor of iNOS, prior to LPS challenge significantly blocked the negative inotropic effect. The se results suggest that ET-1 augments the NO-mediated cardiac contractile depression induced by LPS and the accompanying increase in coronary resistance.
\end{abstract}

Keywords - Coronary perfusion pressure, contraction, LPS, nitric oxide, endothelin

\section{INTRODUCTION}

The isolated heart has been used widely as a model to explore the actions of drugs that affect cardiovascular efficiency. The Langendorff technique is a classical means of measuring the contractile status of the myocardium. Coronary perfusion pressure in the Langendorff system is an important parameter that reflects the effects drugs on coronary artery resistance.

Cardiovascular dysfunction induced by lipopolysaccharide (LPS) has long been of great concern. LPS, an integral part of the outer layer of the gram-negative bacterial cell wall, stimulates a systemic inflammatory process and the production of proinflammatory cytokines and vasoactive mediators [1,2]. Endothelin-1 (ET -1) and nitric oxide (NO) are known to markedly increase during LPS challenge [3]. But no direct experimental evidence from the isolated heart (i.e., in the absence of neural and humoral factors) has clarified the interaction between ET - 1 and NO in the coronary arterial and cardiac inotropic responses after LPS treatment.

In the present study, we used the Langendorff preparation to investigate the roles of ET -1 and NO in LPSinduced coronary vasoconstriction and cardiac depression.

\section{METHODOLOGY}

(1) Preparation of isolated rat hearts

All experiments were carried out on male SpragueDawley rats (240-300g). Immediately after decapitation, the heart was rapidly excised and rinsed in $4^{\circ} \mathrm{C} \mathrm{Krebs-Henseleit}$ buffer (composition in $\mathrm{mM}: \mathrm{NaCl} 118, \mathrm{NaHCO}_{3} 25, \mathrm{KCl} 4.7$, $\mathrm{MgSO}_{4} 1.2, \mathrm{CaCl}_{2} 1.4, \mathrm{KH}_{2} \mathrm{PO}_{4} 1.1$, glucose $11, \mathrm{pH} 7.4$ )

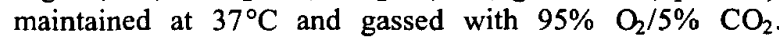
Within 1 min the heart was mounted on the Langendorff apparatus, and perfused at a constant flow $\left(8 \mathrm{ml} \cdot \mathrm{min}^{-1}\right)$.

(2) Experimental setup and data processing

A. Experimental setup

The coronary perfusion pressure (CPP) was continuously recorded by a pressure transducer connected to a computer. A fluid-filled latex balloon was introduced through the mitral valve into the left ventricle. The balloon was connected via a short plastic tube to another pressure transducer and computer for measurement of left ventricular developed pressure (LVDP), heart rate (HR), and maximal rate of rise/fall of ventricular pressure $(+/-\mathrm{dP} / \mathrm{dtmax})$.

$B$. The principle of coronary perfusion pressure measurement

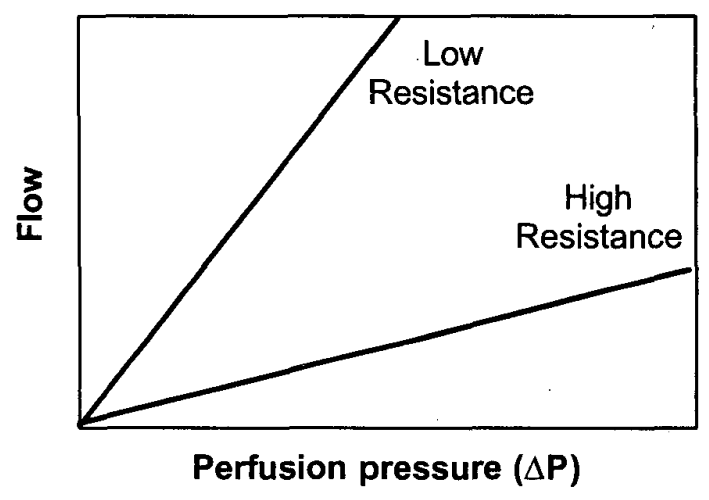

Fig 1. Relationships between pressure, flow and vascular resistance

In the present study the heart was perfused at a constant flow of $8 \mathrm{ml} \mathrm{min}^{-1}$ and the CPP in the perfusion tubing was continuously recorded. Under the constant flow, the pressure reflects the resistance of the coronary artery.

C. Experimental protocols

Rats received a bolus intraperitoneal injection of LPS $\left(10 \mathrm{mg} \mathrm{kg}^{-1}\right)$. After $4 \mathrm{~h}$, the animals were killed and the hearts 
rapidly excised for ex vivo perfusion by the Langendorff technique (LPS group).

In experiments examining the effects of endothelin, the selective ET-1 type A receptor antagonist BQ- $123(0.8 \times 10$ ${ }^{6} \mathrm{~mol} \mathrm{~kg}^{-1}$ ) was given $15 \mathrm{~min}$ before the LPS injection and $4 \mathrm{~h}$ later the animals were killed for isolated heart perfusion (BQ-123+LPS group).

To investigate the effects of nitric oxide, aminoguanidine (AMG) (100 $\mathrm{mg} \mathrm{kg}^{-1}$ ), an inhibitor of inducible nitric oxide synthase (iNOS), was given immediately before injection of BQ-123.15 min later LPS was administered. The hearts were removed for isolated perfusion $4 \mathrm{~h}$ after LPS challenge (AMG+BQ-123+LPS group)

Separate sets of hearts from rats not exposed to LPS served as controls.

\section{Data analysis and statistics}

Data were expressed as mean $\pm \mathrm{SD}$. Comparisons between multiple groups were made by one-way ANOVA followed by the Student-Newman-Keuls post hoc test $\mathrm{P}<0.05$ was considered statistically significant.

\section{RESULTS}

A. Involvement of endothelin-1 in LPS-induced coronary vasoconstriction

Exposure to LPS caused a marked rise in CPP compared with controls $(n=8)$. This response was maintained over a prolonged period (at least $60 \mathrm{~min}$ ). The vasoconstriction following LPS exposure was abolished by pretreatment with $\mathrm{BQ}-123\left(0.8 \times 10^{-6} \mathrm{~mol} \mathrm{~kg}^{-1}, \mathrm{n}=7\right)$, while BQ-123 had no significant effect in control hearts. In addition, there was no significant change in CPP in the $A M G+B Q-123+L P S$ group $v s$ the BQ-123+LPS group (Fig. 2).

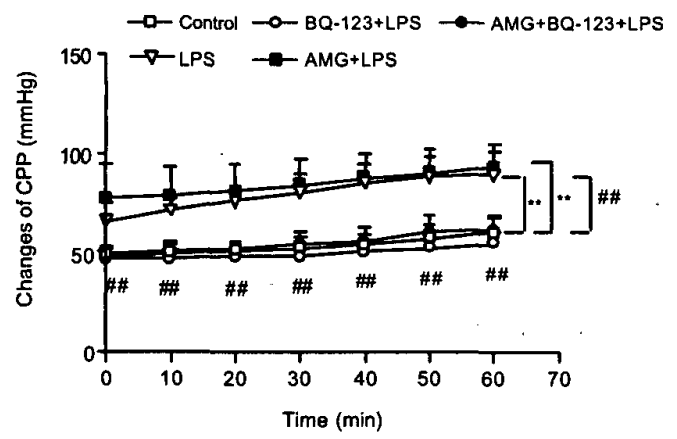

Fig. 2. The effect of $B Q-123$ with or without $A M G$ on the increase of CPP induced by LPS. Data expressed as mean $\pm S D, n=7.8{ }^{* *} p<0.01$, LPS and AMG+LPS groups vs control; \#p<0.01, BQ-123+LPS and AMG+BQ-

$123+$ LPS groups vs LPS group

B. Effects of ET-1 and NO on the contraction of isolated rat hearts following LPS challenge
LPS challenge depressed cardiac contractile function. LVDP, the product of LVISP and HR (LVDPXHR) and $\pm \mathrm{dP} / \mathrm{dtmax}$ decreased markedly. Treatment with $\mathrm{BQ} 123$ alone prior to LPS administration partially reversed the inhibitory action of LPS on sardiac contraction. BQ-123 in the presence of AMG $\left(100 \mathrm{mg} \mathrm{kg}^{-1}\right)$ significantly blocked the cardiac depression induced by LPS exposure (Fig. 3.).

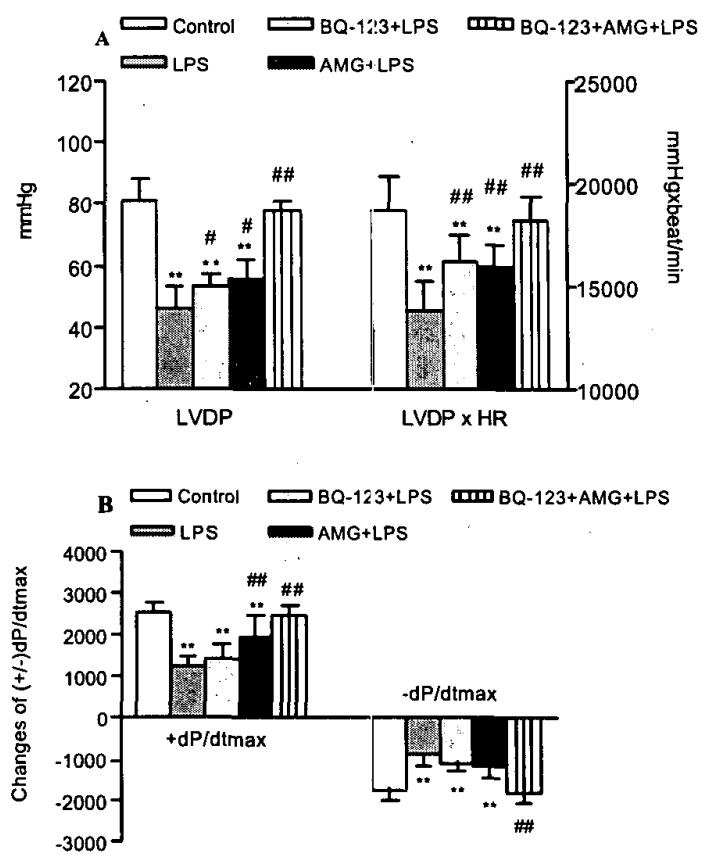

Fig. 3. Effect of $B Q-123$ with or vithout $A M G$ on LPSinduced cardiac depression. Data expressed as mean $\pm S D, n=7-8 .{ }^{* *} p<0.01$ vs control; $\#$ \#p $<0.01$ vs LPS group

\section{DISCUSSION}

The isolated heart is a classical experimental preparation used to define the alterations of inotropic properties under pathological conditions without the complicating influences of autonomic innervation and circulating hormones. In the present study, according to the relationship Pressure $\propto$ flow $\times$ resistance, we used isolated rat hearts perfused at a constant flow by the Langendorff technique to determine alterations in the coronary arterial response of hearts that had experienced LPS challenge. We found that administration of LPS caused a sustained increase in coronary perfusion pressure, which was significantly attenuated by administration of the ET-1 type A receptorselective antagonist $B Q-123$. It is known that ET-1 is a novel endothelium-derived vasoconstrictive peptide. Bacterial endotoxin and cytokine mediators released in response to endotoxin induce ET-1 gene expression and 
stimulate ET-1 protein secretion [4]. In a number of species, LPS increases circulating ET-1 levels 2 - to 10 -fold in vivo [5]. The actions of ET-1 are mediated by $\mathrm{ET}_{\mathrm{A}}$ and $\mathrm{ET}_{\mathrm{B}}$ receptors. $\mathrm{ET}_{\mathrm{A}}$ is the principal constrictor receptor, whereas $\mathrm{ET}_{\mathrm{B}}$ has mixed actions: direct constriction and nitric oxidedependent vasodilation. $\mathrm{ET}_{\mathrm{A}}$ receptors are the predominant receptors in the coronary arteries, accounting for $>85 \%$ of all ET receptors [6]. Hori and his co-workers also observed that rat coronary vasculature expresses the $\mathrm{ET}_{\mathrm{A}}$ receptor subtype [7]. Thus we used BQ-123, a highly specific ET A $_{A}$ receptor antagonist to probe the effect of ET-1 in rat coronary arteries. It has been demonstrated that ET-1 inhibits cytokine-induced iNOS mRNA expression [8] and dose-dependently inhibits cGMP production by the nitric oxide donor sodium nitroprusside [9]. Together, these lines of evidence indicate that the increase in coronary perfusion pressure induced by LPS exposure is due to a pronounced release of ET -1.

Many studies have pointed out that LPS activates iNOS, which contributes to the myocardial depression accompanying sepsis [10] [11]. Cardiac iNOS expression increases several hours after exposure to LPS, with a peak after $6 \mathrm{~h}$ [12]. In the present study, these effects were significantly blocked by AMG, indicating that nitric oxide mediated the cardiac depression. The intracelluar mechanism involves the stimulation of soluble guanylate cyclase to increase intracellular levels of cGMP with a subsequent reduction in intracellular calcium. Brady and his colleagues showed that the stable cGMP analogue, 8bromoguanosine 3',5'-cyclic monophosphate, caused a concentration-related reduction in myocyte contractility and this effect was reversed by methylene blue, an inhibitor of guanylate cyclase [13]. These findings further confirm that NO acts by elevating intracellular levels of cGMP.

In the present study, we observed that pretreatment with BQ-123 partially reversed the negative inotropic effect induced by exposure to LPS. We have shown that LPS treatment induces the production of ET-1, leading to a marked and long lasting coronary vasoconstriction. Hence, the coronary resistance increased, which may cause myocardial ischemia and so depress cardiac function. Thus we predict that ameliorating the blood supply of coronary arteries would help to reverse the depression of cardiac contractility induced by LPS. In addition, the NO-mediated vasodilatation is somewhat endotheliumdependent [14], so a pronounced coronary resistance develops following endothelial injury. Also, because ET-1 is able to inhibit iNOS mRNA expression, we confirm that ET -1 causes coronary vasoconstriction as well as augmenting cardiac depression.

\section{ACKNOWLEDGMENT}

This work was funded by Zhejiang Provincial Foundation for Returnees (No. 419100-N40277).

\section{REFERENCES}

[1] M. P. Glauser, G. Zanetti, J. D. Baumgartner, and J. Cohen, "Septic shock: pathogenesis," Lancet, vol. 338, no. 8769, pp. 732-736, Sept.1991.

[2] J. E. Parrillo, M. M. Parker, C. Natanson, A. F. Suffredini, R. L. Danner, R. E. Cunnion, and F. P. Ognibene, "Septic shock in humans. Advances in the understanding of pathogenesis, cardiovascular dysfunction, and therapy," Ann.Intern.Med., vol. 113, no. 3, pp. 227-242, Aug. 1990 .

[3] T. Hohlfeld, P. Klemm, C. Thiemermann, T. D. Warner, K. Schror, and J. R. Vane, "The contribution of tumour necrosis factor-alp ha and endothelin-1 to the increase of coronary resistance in hearts from rats treated with endotoxin," Br.J.Pharmacol., vol. 116, no. 8, pp. 3309-3315, Dec.1995.

[4] B. H. Pannen, M. Bauer, J. X. Zhang, J. L. Robotham, and M. G. Clemens, "A time-dependent balance between endothelins and nitric oxide regulating portal resistance after endotoxin," Am.J.Physiol, vol. 271, no. 5 Pt 2, pp. H1953-H1961, Nov.1996.

[5] B. Battistini, M. A. Forget, and D. Laight, "Potential roles for endothelins in systemic inflammatory response syndrome with a particular relationship to cytokines," Shock, vol. 5, no. 3, pp. 167-183, Mar.1996.

[6] A. P. Davenport, G. O'Reilly, and R. E. Kuc, "Endothelin ETA and ETB mRNA and receptors expressed by smooth muscle in the human vasculature: majority of the ETA sub-type," Br.J.Pharmacol., vol. 114, no. 6, pp. 1110-1116, Mar. 1995.

[7] S. Hori, Y. Komatsu, R. Shigemoto, N. Mizuno, and S. Nakanishi, "Distinct tissue distribution and cellular localization of two messenger ribonucleic acids encoding different subtypes of rat endothelin receptors," Endocrinology, vol. 130, no. 4, pp. 18851895, Apr.1992.

[8] K. F. Beck, M. G. Mohaupt, and R. B. Sterzel, "Endothelin-1 inhibits cytokine-stimulated transcription of inducible nitric oxide snthase in glomerular mesangial cells," Kidney Int., vol. 48, no. 6, pp. 1893-1899, Dec.1995.

[9] G. Pussard, J. P. Gascard, I. Gorenne, C. Labat, X. Norel, E. Dulmet, and C. Brink, "Endothelin-1 modulates cyclic GMP production and relaxation in human pulmonary vessels," J.Pharmacol.Exp.Ther, vol. 274, no. 2, pp. 969-975, Aug. 1995.

[10] A. J. Brady, P. A. Poole-Wilson, S. E. Harding, and J. B. Warren, "Nitric oxide production within cardiac myocytes reduces their contractility in endotoxemia," Am.J.Physiol, vol. 263, no. 6 Pt 2, pp. H1963-H1966, Dec. 1992. 
[11] S. Tao, and T. M. McKenna, "In vitro endotoxin exposure induces contractile dysfunction in adult rat cardiac myocytes," Am.J.Physiol, vol. 267, no. 5 Pt 2, pp. H1745-H1752, Nov.1994.

[12] R. Schulz, E Nava, and S. Moncada, "Induction and potential biological relevance of a $\mathrm{Ca}(2+)$ independent nitric oxide synthase in the myocardium," Br.J.Pharmacol., vol. 105, no. 3, pp. 575-580, Mar. 1992.

[13] A. J. Brady, J. B. Warren, P. A. Poole-Wilson, T. J. Williams, and S. E. Harding, "Nitric oxide attenuates cardiac myocyte contraction," Am.J.Physiol, vol. 265, no. 1 Pt 2, pp. H176-H182, July1993.

[14] A. R. Baydoun, R. D. Foale, and G. E. Mann, "Bacterial endotoxin rapidly stimulates prolonged endotheliumdependent vasodilatation in the rat isolated perfused heart," Br.J.Pharmacol.; vol. 109, no. 4, pp. $987-991$, Aug. 1993. 